\title{
Mothers' views on feeding infants around the time of weaning
}

\author{
Ruth B Walker ${ }^{1}$, Jennifer A Conn ${ }^{1}$, Michael J Davies ${ }^{2}$ and Vivienne M Moore ${ }^{1, *}$ \\ 'Department of Public Health, University of Adelaide, Adelaide, South Australia 5005, Australia: ${ }^{2}$ Research Centre \\ for Reproductive Health, Department of Obstetrics \& Gynaecology, University of Adelaide, Adelaide, Australia
}

Submitted 22 June 2005: Accepted 21 November 2005

\begin{abstract}
Objective: To describe women's views about aspects of infants' diets around the time of weaning, making comparisons with national guidelines.

Design: A survey of women with a 9-month-old child.

Setting: Adelaide, South Australia.

Subjects: Five hundred and five women who joined a longitudinal study during pregnancy.

Results: Sources of information varied, with written material most commonly used (37\%). Cows' milk was considered suitable as the main drink for weaned infants by $14 \%$ of women. There were divergent views about the suitability of eggs, with many women concerned about allergy. The majority of women (84\%) viewed fruit juice as suitable although many qualified their response, often by stating that fruit juice should be diluted. Almost all women considered the amount of sugar mattered, primarily because of tooth decay, and that salt mattered although the reason was often uncertain. It was widely believed (77\%) that additives in food could cause health problems, in particular hyperactivity and allergies, and half of the women reported avoiding specific foods because of concerns about allergies. Many women thought that giving their child food that was high in fat would encourage a liking for 'junk' food or lead to fatness in adulthood.

Conclusions: There is considerable diversity in the views women express about aspects of infant feeding that have been the subject of guidelines. Further health promotion efforts are needed to achieve greater consistency with recommendations and to address other concerns women have. This will entail greater engagement with parents and shared development of responses.
\end{abstract}

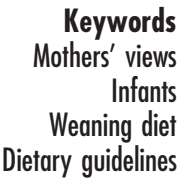

In the 12 months following birth, infants experience very rapid growth and development. An appropriate diet is important to meet nutritional needs while taking into account the immaturity of the gastrointestinal system. Breast milk, exclusively, is the ideal food for the first six months, with solid food introduced gradually thereafter ${ }^{1}$. The term 'weaning' is used to describe the process of introducing solid foods to breast- or formula-fed infants ${ }^{2}$. Parents need to be aware not only of the recommended timing for this transition in feeding, but also of suitable foods, and ways in which the infant diet should differ from that of older children.

In 1992 the Australian National Health and Medical Research Council (NHMRC) issued the Dietary Guidelines for Australians ${ }^{3}$, followed in 1995 by the Dietary Guidelines for Children and Adolescents ${ }^{4}$ (hereafter referred to as the 1995 Guidelines). The latter included specific recommendations for the weaning period which, in summary, were: breast milk should be the sole food for infants for the first 4 to 6 months of life; solid food can be introduced from 4 to 6 months of age; new foods should be offered no more frequently than each 4 or 5 days initially, to avoid confusion and to rule out the possibility of food allergy or sensitivity; cows' milk is not recommended as the main drink before 12 months of age, principally due to the low iron content; fruit juice is less preferable to fresh or cooked fruit as it reduces the nutrient density of the fruit component of the diet; no salt, sugar or other material should be added to infant foods; reduced-fat milks and lowfat diets are not generally recommended in the first two years of life; and vitamin supplements are not necessary for healthy, full-term infants ${ }^{4}$.

In addition to formal dietary guidelines, information designed especially for parents is available from a number of sources. Pamphlets are distributed to women in 'Bounty' bags during pregnancy and following the birth. Written and verbal information is offered by the South Australian state government agency, Child and Youth Health (CYH). Approximately 85\% of all children born in the state are enrolled with CYH for routine health checks and parenting support5 ${ }^{5}$. Food manufacturers such as Heinz also produce brochures about feeding infants that are available through outlets such as supermarkets or chemists. 
While breast-feeding is monitored in national health surveys $^{6}$ and by state governments, there is limited information on other dietary practices during infancy. Retallack et al. ${ }^{7}$ conducted a survey in a South Australian shopping centre and reported that $10 \%$ of infants aged $6-8$ months were being fed cows' milk. Also, the age at which solid food was introduced was frequently less than recommended, with a third of children aged 2-4 months receiving some solids. More recent surveys conducted in Britain $^{8-10}$ and Australia ${ }^{11}$ have highlighted similar discrepancies between nutritional recommendations and parental practices.

Information on parents' interpretations of the basis for nutritional recommendations, or rationales for alternative practices, has rarely been sought ${ }^{8}$. Furthermore, there is little information about the extent of concerns which parents may have that are not a focus of guidelines and dietary surveys. For example, food avoidance due to concerns about allergies could be widespread.

Research to gain understanding of community (or lay) knowledge has been growing, in relation to both public health issues generally ${ }^{12}$ and nutritional matters ${ }^{13,14}$. This line of inquiry is important in order to move beyond the 'knowledge deficit' model that underpins traditional nutrition education efforts ${ }^{14,15}$, characterised by one-way transmission of facts. This is not to argue that community views should go unchallenged, but rather that a dialogue is necessary. Appreciating the diversity of views held by community members is an important first step in this process.

We therefore sought, first, to describe the views of mothers about aspects of infants' diets during the weaning period and, second, to make some comparisons with national guidelines. We focused on cows' milk, eggs, fruit juice, sugar, salt, food additives and vitamin supplements. In addition, we examined avoidance of certain foods for infants because of concerns about asthma or allergies and the extent to which women believed that dietary fat in infancy would promote later obesity. We do not intend the findings to be interpreted as 'a clash of objective expert knowledge and subjective lay distortions, ${ }^{13}$, but rather offer them to encourage further research and discussion about these differences and appropriate responses.

\section{Methods}

We surveyed 505 women with a 9-month-old child in 1999-2001, as part of a longitudinal study of child growth and development. The children were born to women who participated in a prospective observational study of foetal growth.

At baseline, women were identified prior to 16 weeks of pregnancy through the antenatal clinic at a public hospital and through the rooms of three privately practising obstetricians. At the hospital, women were approached using a random schedule, while at the private practices all eligible women were invited to join the study. The eligibility criteria included being Caucasian, aged at least 18 years and free from certain conditions known to affect foetal growth ${ }^{16}$.

The 557 women and children who completed the initial study of foetal growth comprised $96 \%$ of those who joined the study and gave birth to a baby that survived the neonatal period. As intended, the sampling strategy meant that participating women were comparable to all women having children in South Australia in 1998-2000 ${ }^{16}$. Over 90\% of births in the state are to Caucasian women, with more than $95 \%$ of women aged at least 18 years ${ }^{17}$.

When the child reached 9 months of age, women were interviewed at their home or one of our offices, as they preferred. Eighty-five per cent of women were interviewed within two weeks of the target date (not adjusted for prematurity). The study had ethics approval from the University of Adelaide and written consent was obtained from all participants.

The interview schedule included questions about family circumstances and sources of information on infant feeding, as well as selected practices and views about the suitability for weaned infants of cows' milk, eggs, fruit juice, sugar, salt and vitamin supplements. A mix of open and closed questions was used, and participants were also asked to indicate their agreement or disagreement with a set of statements using a 5-point Likert scale. The interview schedule was piloted and the two research nurses who undertook all of the interviews received training and regular review to standardise prompts and recording of information. The interviewers recorded all responses on a special form, later entered into an Access database.

We used the World Health Organization definition of 'full' breast-feeding, which encompasses the child receiving breast milk either 'exclusively' or 'predominantly' with water or other fluid given infrequently ${ }^{18}$. Information about breast-feeding and introduction of solids was collected prospectively, in interviews undertaken when the child was 3 and 6 months of age.

Categorical responses to closed questions were tabulated to obtain frequencies using SPSS 11.0 for Windows (SPSS Inc., Chicago, IL, USA). Where it was pertinent to use the prevalence obtained in our sample to provide an estimate for the wider community, 95\% confidence intervals (CI) were calculated using Epi Info Version 3.2 (Centers for Disease Control and Prevention, Atlanta, GA, USA).

Content analysis was used to identify and classify sets of responses to open-ended questions ${ }^{19}$. Creation of categories and coding was undertaken by a nutritionist (J.A.C.). The text of the free responses was first read through several times to gain a sense of the whole, and then divided into content areas and 'meaning units' (collections of words or statements that related to the same central meaning). Meaning units were then condensed and coded. Categories were reviewed by another member of the 
research team (R.B.W.) to ensure accuracy and objectivity. Selected quotations from the open-ended responses are presented in the results to illustrate relevant concepts.

\section{Results}

Interviews were completed by 505 women with a 9month-old child. The mothers and their children were part of a longitudinal study in which there were 557 families at the time of birth. Eight of the 557 women (1\%) withdrew prior to their child reaching 9 months of age (one because her child died) and a further 36 women (6\%) were unable to be interviewed at that point in time although they wished to continue being involved. Information was obtained from 513 women, but contributions from eight women were limited due to, for example, time constraints or being interstate. The 505 women with adequate data comprised $91 \%$ of the birth cohort. For three children, the father was the primary caregiver and provided substantial information; however, for simplicity, this is not reported separately and demographic details of mothers rather than fathers are given.

Compared with the 505 mothers from whom information was obtained, the 52 mothers of children for whom information was limited or not available at this time point were more likely to be under 30 years of age (71\% vs. 53\%), more likely to have left high school early (46\% vs. 33\%), and their distribution of household income was shifted to the left (20\% with household income less than 20799 Australian dollars (AUD) vs. 13\%). Chi-square tests comparing these characteristics across the relevant categories yielded $P=0.01, P=0.07$ and $P<0.01$, respectively. Birth weight and sex distributions of the children in the two groups were similar, as was the proportion first-born, but children for whom information was limited or not available at this time point were somewhat less likely to have been breast-fed at 3 months of age ( $40 \%$ breast-fed vs. $54 \%$ ) although this difference was not statistically significant. Thus, as expected, there were demographic differences between families who participated and those for whom information was missing. However, incomplete or non-responses were below $10 \%$ and the sample with data was still broadly representative of the wider community, as described below.

Table 1 provides a description of participating women and children. The ages of women ranged from 19 to 43 years, with a mean age of 31 years (standard deviation 5 years). Around 90\% of women lived with their partner. For about one-third of women, this was their first child. Socio-economic background was indicated by mother's educational attainment and household income. Approximately one-third had not completed high school, while one-fifth had a university degree.

At baseline, our sample was demographically comparable to all women who gave birth in South Australia in the corresponding period, as described previously ${ }^{16}$, in terms of their age, educational attainment, employment status, household income, relationship status and family size. Families remained demographically comparable 9 months later. Approximately 50\% of South Australian women with children aged less than 4 years are not in paid employment ${ }^{20}$. The average weekly income of Australian couples with an eldest child under 5 years old in 1997/98 was AUD 973, approximately AUD 50600 per annum ${ }^{21}$.

There were 250 boys and 255 girls in the sample. The majority of children (94\%) had been born at term (at least 37 weeks of gestation). Both the proportion of children born prematurely and the distribution of birth weight for the sample were very similar to those for all children born in South Australia in the same period ${ }^{17}$. At the time of the interview, the majority of children (85\%) were within two weeks of being exactly 9 months old.

Sixty-eight of the children (13.5\%, 95\% CI 10.7-16.7) were never breast-fed (Table 1). By 16 weeks of age, 32\% of infants (95\% CI 28.1-36.2) had been introduced to solid food. Usually this meant that the child had started to eat rice cereal, but occasionally other practices marked the introduction of solids. For example, one child was given boiled cows' milk with mashed biscuit in a bottle. At 9 months of age 31\% were still breast-fed (95\% CI 26.634.6). Nearly $90 \%$ of women indicated they were the family member who usually prepared the food for their child and almost half usually gave their child home-made food. Over a third of women reported that written information was a main source of information, with

\section{Table 1 Characteristics of mothers and infants}

\begin{tabular}{|c|c|c|}
\hline Characteristic & $n$ & $\%$ \\
\hline \multicolumn{3}{|l|}{ Mother } \\
\hline Age $<30$ years & 213 & 42.1 \\
\hline First-time mother & 171 & 33.9 \\
\hline \multicolumn{3}{|l|}{ Educational attainment } \\
\hline Partial secondary school & 168 & 33.3 \\
\hline Completed secondary school & 89 & 17.6 \\
\hline Technical qualification & 152 & 30.1 \\
\hline University degree & 96 & 19.0 \\
\hline \multicolumn{3}{|l|}{ Annual household income (AUD) } \\
\hline $0-20799$ & 63 & 12.5 \\
\hline $20800-31199$ & 92 & 18.2 \\
\hline $31200-41599$ & 82 & 16.2 \\
\hline $41600-51999$ & 71 & 14.1 \\
\hline $52000+$ & 192 & 38.0 \\
\hline Not known & 5 & 0.9 \\
\hline Currently in paid employment & 165 & 32.6 \\
\hline \multicolumn{3}{|l|}{ Infant } \\
\hline Female & 255 & 50.5 \\
\hline Male & 250 & 49.5 \\
\hline \multicolumn{3}{|l|}{ Extent of breast-feeding } \\
\hline Never breast-fed & 68 & 13.5 \\
\hline Breast-fed at 3 months & 275 & 54.5 \\
\hline Breast-fed at 6 months & 215 & 42.6 \\
\hline Breast-fed at 9 months & 154 & 30.5 \\
\hline Solids introduced less than 16 weeks & 162 & 32.1 \\
\hline $\begin{array}{l}\text { Allergies or eczema diagnosed by } \\
\text { medical practitioner }\end{array}$ & 93 & 18.4 \\
\hline Regularly in some form of childcare & 263 & 52.0 \\
\hline
\end{tabular}

AUD - Australian dollars. 
relatively small proportions relying on health professionals or their mother (Table 2).

Women were asked whether cows' milk was suitable as the main drink for children under 12 months of age, who had been weaned. As shown in Table 3, 73 women (14\%) viewed cows' milk as suitable. Among the 401 (79\%) who considered cows' milk unsuitable, two sets of explanations emerged. One set (voiced by 253 women) reflected concerns over the nutritional content or problems with digestion. These concerns were usually expressed in terms such as: 'doesn't have the vitamins and minerals that formula has', 'not enough of all the nutrition they need at this age', 'lacks some of the extra goodies that the formula has'. The other set of reasons concerned allergies or intolerance (articulated by 45 women): 'higher incidence of eczema and asthma', 'causes constipation', 'they can't tolerate it'. However, a substantial number of those who thought cows' milk unsuitable $(n=92)$ could not provide a reason or offered a general view such as: 'breast milk is better', 'cows' milk is for cows'.

Opinions varied about the suitability of eggs for infants who had commenced solid food (Table 3), with four positions emerging, including those not sure. There were 177 women (35\%) who viewed eggs as suitable, without qualification. A further 154 women (30\%) thought eggs were suitable but qualified this response. Most notably, 91 women believed that egg yolk only was suitable. The kinds of reasons given for egg yolk only being suitable were: 'egg yolk is fine; white is too heavy for their digestive system', 'whites not recommended; reaction if they have eczema', 'yolk only; most children under 12 months are allergic to the white'. There were 120 women (24\%) who considered eggs unsuitable for infants; many of these women $(n=50)$ mentioned the possibility of allergies, asthma or eczema, but some $(n=12)$ could not say why eggs were unsuitable.

Table 2 Mother's main sources of information about choosing food for children*

\begin{tabular}{lrr}
\hline Source & $n$ & $\%$ \\
\hline Family and friends & & \\
$\quad$ Mothers & 62 & 12.3 \\
$\quad$ Other relatives (including mother-in-law, & 37 & 7.3 \\
$\quad$ family, parents, sister or grandparents) & & \\
$\quad$ Friends & 20 & 4.0 \\
Health professionals & 76 & 15.0 \\
$\quad$ Child and Youth Health (state government & & \\
$\quad$ organisation) & 10 & 2.0 \\
$\quad$ General practitioner or specialist & & \\
Written material & 189 & 37.4 \\
$\quad$ Books, brochures & 5 & 1.0 \\
$\quad$ Supermarket or advertising & 137 & 27.1 \\
Other & 60 & 11.9 \\
$\quad$ Previous experience & 5 & 1.0 \\
$\quad$ Common sense & 10 & 2.0 \\
$\quad$ Many different sources & \\
$\quad$ Don't know & & \\
\hline
\end{tabular}

${ }^{\star}$ Women could indicate more than one main source.
Table 3 Appropriateness of dietary items for infants around the time of weaning

\begin{tabular}{|c|c|c|c|c|c|c|}
\hline \multirow[b]{2}{*}{ Aspect of diet } & \multicolumn{2}{|c|}{ Suitable } & \multicolumn{2}{|c|}{$\begin{array}{l}\text { Not suit- } \\
\text { able }\end{array}$} & \multicolumn{2}{|c|}{ Not sure } \\
\hline & $n$ & $\%$ & $n$ & $\%$ & $n$ & $\%$ \\
\hline $\begin{array}{l}\text { Is cows' milk, as the main drink, } \\
\text { suitable? }\end{array}$ & 73 & 14.4 & 401 & 79.4 & 31 & 6.1 \\
\hline Are eggs suitable? & 331 & 65.5 & 120 & 23.7 & 54 & 10.6 \\
\hline \multirow[t]{3}{*}{ Is fruit juice suitable? } & 426 & 84.3 & 74 & 14.6 & 5 & 0.9 \\
\hline & \multicolumn{2}{|c|}{ No } & \multicolumn{2}{|c|}{ Yes } & \multicolumn{2}{|c|}{ Not sure } \\
\hline & $n$ & $\%$ & $n$ & $\%$ & $n$ & $\%$ \\
\hline $\begin{array}{l}\text { Does it matter how much } \\
\text { sugar is in infant foods? }\end{array}$ & 11 & 2.1 & 480 & 95.0 & 14 & 2.7 \\
\hline $\begin{array}{l}\text { Does it matter how much } \\
\text { salt is in infant foods? }\end{array}$ & 12 & 2.3 & 477 & 94.4 & 16 & 3.1 \\
\hline $\begin{array}{l}\text { Do you think food additives } \\
\text { can cause health problems in } \\
\text { young children? }\end{array}$ & 39 & 7.7 & 388 & 76.8 & 78 & 15.4 \\
\hline $\begin{array}{l}\text { Do children under the age } \\
\text { of } 12 \text { months commonly need } \\
\text { vitamin supplements? }\end{array}$ & 386 & 76.4 & 92 & 18.2 & 27 & 5.3 \\
\hline
\end{tabular}

The majority of women $(n=426,84 \%)$ viewed fruit juice as suitable, although almost half of this group $(n=202)$ made additional comments (Table 3). Many women ( $n=130)$ qualified their positive response with a statement to the effect that the juice needed to be diluted. Only 10 women offered an explanation for the need to dilute juice, including: 'he could get used to it; I would rather they drink water', 'otherwise too strong for their systems; could cause diarrhoea; constipation; nappy rash from acidity'. Other sets of qualified responses reflected the ideas that fruit juice was suitable in moderation or if natural (no added sugar or preservatives). There were 74 women (15\%) who considered fruit juice unsuitable for infants, with a subset $(n=45)$ concerned about the sugar content, while others could not articulate a reason.

Women were asked 'Does it matter how much sugar is in infant foods?' (Table 3). Only 11 women (2\%) thought it did not matter. Of those who considered sugar to be an issue, just over half ( $n=263$ ) mentioned tooth decay as a reason and almost one-third $(n=147)$ mentioned that adding sugar could promote poor eating habits: 'they get too used to it and won't like foods without added sugar', 'don't want him to get addicted to sugary foods'. Some women mentioned that infants simply do not need added sugar $(n=48)$, or that sugar causes hyperactivity $(n=38)$.

Almost all women $(477,95 \%)$ thought it mattered how much salt was in infant food (Table 3), although many $(n=236)$ could not explain why they held this view, for example: 'don't know, it's the way I have been brought up', 'just not good for you, enough salt in everything without adding it', 'not healthy but can't remember why', 'not good for them or anyone'. Among those who offered a rationale, there were three main ideas: salt is not good for body organs $(n=136)$; promotes bad eating patterns $(n=64)$; can 
cause death in children $(n=41)$. Most of the latter women explicitly referred to a then-recent media story regarding a British child dying as a result of excessive salt intake.

The majority of women $(n=388,77 \%)$ believed that additives in food could cause 'health problems' in young children (Table 3). When asked to specify the sorts of health problems, hyperactivity was the most common response $(n=238)$. Women communicated hyperactivity in a variety of ways, including: 'makes kids go stupid', 'colouring and preservatives can send them crazy; things like red and green, cordial, snack foods', 'they become psychopaths [said jokingly]; become a bit weird', 'lack of attention span; fidgety; disobedient child; boisterous'. Allergies, asthma or eczema was the next most common health problem mentioned $(n=141)$.

Women were presented with a list of 10 foods (eggs, peanut paste, cows' milk, orange, tomato, cheese, yoghurt, fish, soy milk and rice) and asked whether they had avoided giving their child any of the foods because they thought it might increase the risk of allergies and, separately, asthma. Half of the woman (255, 50\%) had avoided one or more food item due to concerns about allergy. Reports of avoidance due to allergy chiefly related to three items, eggs, peanut paste and cows' milk. In contrast, less than $10 \%$ had avoided a listed food due to concern about asthma. The item most often avoided for this reason was cows' milk, although this was avoided by only 24 women.

Several statements about dietary fat were presented and women were asked to indicate the extent to which they agreed or disagreed with each statement (Table 4). Only a small proportion of women agreed that children should have fat-reduced milk after age 2 or 5 years. However, 80 women (16\%) agreed (strongly or somewhat) with the more general statement that the fat content of a child's diet should be restricted after 2 years of age. Some 131 women (16\%) believed that giving their child food that was high in fat would encourage a liking for 'junk' food and 102 (22\%) believed that it would lead to fatness in adulthood.

\section{Discussion}

In this study we explored women's views about selected aspects of infants' diets around the time of weaning, as a first step towards understanding diversity in practices. Women in the sample were representative of mothers with young children in the wider community in terms of family composition and socio-economic circumstances. As expected, non-participants tended to be from relatively disadvantaged backgrounds, but non-participation was low. The information we collected shows that, in some areas, most women hold views congruent with recommendations made by the NHMRC, but in other areas substantial proportions of women express alternative views. The 1995 Guidelines ${ }^{4}$ form the principal basis for discussion as the study interviews were undertaken in 1999-2001, before publication of the 2003 revision ${ }^{1}$.

As previous surveys have shown ${ }^{11}$, in Australia the proportion of children breast-fed and the duration of breast-feeding are less than desirable from a public health perspective. The proportion of children never breast-fed in this sample (14\%) is almost identical to that obtained in the 2001 National Health Survey ${ }^{6}$. Solid food had been introduced to a third of the infants prior to 16 weeks of age, although the 1995 Guidelines ${ }^{4}$ recommended introduction between 4 and 6 months of age.

Some $14 \%$ of women thought that cows' milk was suitable as the main drink for infants under 12 months, whereas the 1995 Guidelines ${ }^{4}$ stated that cows' milk is not suitable. This proportion is similar to that reported by

Table 4 Views about dietary fat

\begin{tabular}{|c|c|c|c|c|c|c|c|}
\hline \multirow[b]{3}{*}{ Statement } & & \multirow{3}{*}{$\begin{array}{l}\text { No answer } \\
\text { given }\end{array}$} & \multicolumn{5}{|c|}{ Extent of agreement } \\
\hline & & & \multicolumn{2}{|c|}{$\begin{array}{l}\text { Strongly } \\
\text { disagree }\end{array}$} & \multirow[b]{2}{*}{3} & \multicolumn{2}{|c|}{$\begin{array}{l}\text { Strongly } \\
\text { agree }\end{array}$} \\
\hline & & & 1 & 2 & & 4 & 5 \\
\hline \multirow{2}{*}{$\begin{array}{l}\text { After children turn } 2 \text { years old, the fat content of their diet } \\
\text { should be restricted }\end{array}$} & $n$ & 1 & 75 & 205 & 144 & 74 & 6 \\
\hline & $\%$ & 0.2 & 14.9 & 40.6 & 28.5 & 14.7 & 1.2 \\
\hline \multirow[t]{2}{*}{ Fat in the diet should not be restricted for children of any age } & $n$ & 2 & 54 & 184 & 109 & 119 & 37 \\
\hline & $\%$ & 0.4 & 10.7 & 36.4 & 21.6 & 23.6 & 7.3 \\
\hline \multirow[t]{2}{*}{ Children over 2 years should drink fat-reduced milk } & $n$ & 1 & 177 & 247 & 59 & 14 & 7 \\
\hline & $\%$ & 0.2 & 35.0 & 50.0 & 11.7 & 3.0 & 1.4 \\
\hline \multirow[t]{2}{*}{ Children over 5 years should drink fat-reduced milk } & $n$ & 1 & 120 & 252 & 89 & 38 & 5 \\
\hline & $\%$ & 0.2 & 23.8 & 49.9 & 17.6 & 7.5 & 1.0 \\
\hline \multirow{4}{*}{$\begin{array}{l}\text { If I give my child food that is high in fat, he or she will develop } \\
\text { a liking for junk food } \\
\text { If I give my child food that is high in fat, he or she will grow to } \\
\text { be fat as an adult }\end{array}$} & $n$ & 1 & 88 & 180 & 105 & 105 & 26 \\
\hline & $\%$ & 0.2 & 17.4 & 35.6 & 20.7 & 20.7 & 5.1 \\
\hline & $n$ & 1 & 89 & 195 & 116 & 96 & 8 \\
\hline & $\%$ & 0.2 & 17.6 & 38.6 & 23.0 & 19.0 & 1.6 \\
\hline
\end{tabular}


Retallack et $a l^{7}$ a decade ago, based on a shopping centre survey in the same city. Another indication that communication about cows' milk has been less than successful lies in the finding that a subset of women who believed cows' milk was unsuitable were, nevertheless, unable to offer a rationale.

There were divergent views about whether eggs were suitable foods for infants around the time of weaning. Concerns about allergies, eczema and asthma predominated among women who felt that eggs were unsuitable. The 1995 Guidelines $^{4}$ did not include eggs as one of the infant foods that were unsuitable or should be used with care, but a CYH brochure ${ }^{22}$ flagged the potential allergenic nature of eggs. Some women believed that egg yolk only was suitable. Several parent-focused brochures we inspected made a distinction between egg yolk and egg white, indicating that the yolk could be introduced earlier, although the scientific basis for this distinction is not clear.

A range of views was also apparent in relation to the provision of fruit juice to infants around the time of weaning. A minority of women did not think fruit juice was suitable at all, most giving the sugar content as the reason. In this respect, women's views are not incompatible with nutrition professionals' concern that fruit juice displaces energy from more nutritious sources, although when asked more directly about sugar, women tended to refer to dental issues. Around half of the remaining women specified that fruit juice, while suitable, needed to be diluted. There is potential for confusion here between the widely accepted need to dilute fruit juice, which could be seen to reduce the nutrient content, and the argument that consumption should be limited as nutrient density is low.

A subset of women thought that vitamin supplements were commonly needed by young children, due to dietary inadequacy. The 1995 Guidelines ${ }^{4}$ stated that supplements are not necessary for healthy, term infants. Recommendations about vitamin supplements for young children differ between countries, partly because vitamin D status is determined by exposure to sunlight as well as dietary intake $^{23}$. For example, the British Nutrition Foundation suggests breast-fed infants should receive a daily supplement of vitamin D if there is concern over the mother's vitamin D status in pregnancy or the infant's exposure to sunlight ${ }^{2}$. Many Australians have British relatives and ancestry, so this background may contribute to different views.

In general, women thought that it mattered how much sugar and salt was in infant foods. These views are compatible with the 1995 Guidelines ${ }^{4}$. While most women could not articulate a reason for salt being an issue (and the Guidelines gave none), tooth decay featured widely in women's explanations regarding sugar, as did the notion of instigating preferences or habits. Sociological research on sugar and a liking for sweetness suggests that this preference is innate, and that as children develop the preference is constrained by sociocultural and economic factors $^{24}$. It appears from women's responses that they felt they could play a role in encouraging or constraining a preference for sugar.

The prevalence of food allergy is highest among young children and recent increases in prevalence have been documented, but the proportion of children affected is around $5 \%{ }^{25}$. In Australia, the foods most often associated with allergies in children are cows' milk, eggs and peanuts ${ }^{26}$, with only allergy to peanuts likely to persist into adulthood $^{27}$. Women's reports of avoidance closely matched this shortlist of items, but many more women were concerned than might be expected based on the epidemiological risk. Hyperactivity dominated women's widespread concerns about food additives. This is a controversial area ${ }^{28}$ but, again, the degree of concern may be greater than warranted epidemiologically.

In a previous study, Morgan et al. ${ }^{8}$ explored views of women in the UK about infant feeding and they were troubled by the fact that over $80 \%$ of women considered a high fibre intake and a low fat intake important. In our study, most women held views consistent with the 1995 Guidelines ${ }^{4}$ in relation to fat-reduced milk, which is not recommended for infants or toddlers. However, concerns about the fat content of the diet more generally appeared quite widespread. At least one in five women believed that there would be longer-term consequences of giving children high-fat food during infancy, such as a liking for 'junk' food or obesity. The 1995 Guidelines ${ }^{4}$ specified that dietary fat should not be restricted during the first two years of life, because this may compromise intakes of energy and essential fatty acids and could affect growth and development.

Since conducting this study the NHMRC has revised the 1995 Guidelines $^{4}$, with the 2003 version $^{1}$ placing more emphasis on food groups and lifestyle patterns than on specific nutrients. In relation to weaning, a number of recommendations have been strengthened. Exclusive breast-feeding is now recommended for 6 months rather than $4-6$ months. The 2003 Guidelines ${ }^{1}$ explicitly state that fruit juice should not be given before 6 months of age, following which it can be given if diluted; the rationale presented is that fruit juice offers limited nutritional benefits and may lead to decreased nutrient intake from other sources, so intake should be restricted and whole fruit given in preference to fruit juice. A new section details foods that are unsuitable or should be used with care, including honey, tea, nuts, fruit juice and reduced-fat milks. Specific statements about avoiding foods because of food allergy are made: 'If there is a strong history of family allergy, introduction of cheese, yoghurt, ice-cream, fish and wheat cereal should be delayed until 12 months of age. If there is a strong history of peanut allergy, peanut products should be avoided until after 3 years of age'. Breast-feeding and delayed introduction of specific foods are suggested as strategies to provide protection from food allergy in infants with a positive family history but, otherwise, elimination of 
allergenic foods is recommended only after appropriate diagnostic procedures have been carried out.

The orientation of the 2003 Guidelines $^{1}$ and the additional detail provided may be helpful in changing infant dietary practices that are not optimal for child health. However, the Guidelines do not fully engage with some concerns that women have and related practices, for example, those surrounding eggs, additives and dietary fat. Accepting that this is not necessarily the function of guidelines, there remains a need to find avenues for dialogue about these matters. Written material was a main source of information for about a third of women, and a sizeable proportion relied on the state government agency $\mathrm{CYH}$, so there are established paths for communication. However, our study indicates a complexity to these issues that simple educational messages do not acknowledge. Greater engagement with parents and shared development of responses would be appropriate.

\section{Acknowledgements}

We are grateful to the women and children who participated in the Generation 1 Study and also to the partners and other family members who helped to make the study possible. We wish to thank Kendall Smith, Lisa Masters and Deborah Roffe for interviewing women and other data collection, Anthea Page for database programming, Kaye Robinson for data entry and Heather McElroy for contributing to preliminary analyses. The assistance of staff at the Lyell McEwin Health Service, Dr Basil Antonas, Carol Murray, Dr John Svigos, Jane Christiansen, Dr Xen Xenophou, Maryann Baker, other practice staff, and staff at five hospitals where the children were born, was very valuable in establishing the cohort. The encouragement and support of Dr Peter Parodi, Professor Tony Worsley and Professor Jeffrey Robinson are much appreciated. This study was supported by grants from the Dairy Research and Development Corporation, the Faculty of Health Sciences at the University of Adelaide, and the Channel 7 Children's Research Foundation.

\section{References}

1 National Health and Medical Research Council (NHMRC). Dietary Guidelines for Adolescents and Children in Australia - Incorporating the Infant Feeding Guidelines for Health Workers. Catalogue No. 0326111. Canberra: NHMRC, 2003.

2 British Nutrition Foundation. Nutrition in Infancy. Briefing Paper. London: British Nutrition Foundation, 1997.

3 National Health and Medical Research Council (NHMRC). Dietary Guidelines for Australians. Catalogue No. 9218223. Canberra: NHMRC, 1992.

4 National Health and Medical Research Council (NHMRC). Dietary Guidelines for Children and Adolescents. Catalogue No. 9557075. Canberra: NHMRC, 1995.

5 Child and Youth Health. Annual Report 2002/2003. Adelaide: Government of South Australia, 2003.
6 Australian Bureau of Statistics. National Health Survey 2001: Summary of Results. Catalogue No. 4364.0. Canberra: Australian Government Publishing Service, 2002.

7 Retallack SJ, Simmer K, Makrides M, Gibson RA. Infant weaning practices in Adelaide: the results of a shopping complex survey. Journal of Paediatric Child Health 1994; 30: $28-32$.

8 Morgan JB, Kimber AC, Redfern AM, Stordy BJ. Healthy eating for infants - mother's attitudes. Acta Paediatrica 1995; 84: 512-5.

9 Emmett P, North K, Noble S and the ALSPAC Study Team. Types of drinks consumed by infants at 4 and 8 months of age: a descriptive study. Public Health Nutrition 2000; 3: 211-7.

10 Noble S, Emmett P and the ALSPAC Study Team. Food and nutrient intake in a cohort of 8-month-old infants in the South West of England in 1993. European Journal of Clinical Nutrition 2001; 55: 698-707.

11 Donath SM, Amir LH. The introduction of breast milk substitutes and solid foods: evidence from the 1995 National Health Survey. Australian and New Zealand Journal of Public Health 2002; 26: 481-4.

12 Popay J, Williams G. Public health research and lay knowledge. Social Science \& Medicine 1996; 45: 759-68.

13 Hansen J, Holm L, Frewer L, Robinson P, Sandoe P. Beyond the knowledge deficit: recent research into lay and expert attitudes to food risks. Appetite 2003; 41: 111-21.

14 Coveney J. A qualitative study exploring socio-economic differences in parental lay knowledge of food and health: implications for public health nutrition. Public Health Nutrition 2004; 8: 290-7.

15 Crotty P. Good Nutrition: Fact, Fashion in Dietary Advice. St Leonards, New South Wales: Allen and Unwin, 1995.

16 Moore VM, Davies MJ, Willson KJ, Worsley A, Robinson JS. Dietary composition of pregnant women is related to size of the baby at birth. Journal of Nutrition 2004; 134: 1820-6.

17 Chan A, Scott J, Nguyen A-M, Keane R. Pregnancy Outcome in South Australia 1999. Adelaide: Pregnancy Outcome Unit, Epidemiology Branch, Department of Human Services, 2000.

18 World Health Organization (WHO). Baby-Friendly Hospital Initiative. Part 1. Geneva: WHO, 1991.

19 Downe-Wambolt B. Content analysis: method, applications and issues. Health Care for Women International 1992; 13: 313-21.

20 Australian Bureau of Statistics. Australian Social Trends. Catalogue No. 4102.0. Canberra: Australian Government Publishing Service, 2000.

21 Australian Bureau of Statistics. Income Distribution, Australia. Catalogue No. 6523.0. Canberra: Australian Government Publishing Service, 1999.

22 Child and Youth Health. The Feeding Book (for Babies and Young Children). Adelaide: Child and Youth Health, 2002.

23 Lichtenstein PK, Tsang RC. Calcium and vitamin D requirements for 6 to 12 -month-old infants. In: Heird WC, ed. Nutritional Needs of the Six to Twelve Month Old Infant. Carnation Nutrition Education Series, Vol. 2. New York: Raven Press, 1991; 217-27.

24 Beardsworth A, Keil T. Sugar and confectionary: sweetness in the human diet. Sociology on the Menu: An Invitation to the Study of Food and Society. London: Routledge, 1997.

25 Zeiger RS. Food allergen avoidance in the prevention of food allergy in infants and children. Pediatrics 2003; 111: 1662-71.

26 Hill DJ, Hosking CS, Heine RG. Clinical spectrum of food allergy in children in Australia and South-East Asia: identification and targets for treatment. Annals of Medicine 1999; 31: 272-81.

27 Sicherer S. Food allergy. Lancet 2002; 360: 701-10.

28 Eigenmann PA, Haenggeli CA. Food colourings and preservatives - allergy and hyperactivity. Lancet 2004; 364: $823-4$. 